\title{
Preschool Teachers Understanding of Science Identity
}

\author{
Donna Farland-Smith \\ The Ohio State University, Columbus, OH, USA \\ Email: farland-smith.1@osu.edu
}

How to cite this paper: Farland-Smith, D. (2018). Preschool Teachers Understanding of Science Identity. Creative Education, 9, 285-291.

https://doi.org/10.4236/ce.2018.92019

Received: December 20, 2017

Accepted: February 23, 2018

Published: February 26, 2018

Copyright $\odot 2018$ by author and Scientific Research Publishing Inc.

This work is licensed under the Creative

Commons Attribution International

License (CC BY 4.0).

http://creativecommons.org/licenses/by/4.0/

\begin{abstract}
This study utilized a survey to analyze preschool teachers' perceptions of science identity before and after watching an episode of Sid the Science Kid during a professional development. A total of twelve teachers participated in the study by completing pre and post survey questions. The one question that was addressed during this study was how teachers felt about science identity before and after watching the Sid the Science Kid episode? Two notable conclusions were a result of this study 1) preschool teacher's lack of awareness and understanding of science identity; and 2) preschool teacher's appreciation and willingness of students' to role play being a scientist, but little understanding of why this role play is beneficial.
\end{abstract}

\section{Keywords}

Preschool, Science, Identity, Professional Development

\section{Introduction}

An individual's identity is always in continuous development, even if a person has relatively stable perception of "who" one is. At the preschool age, students are just beginning to experiment with their identity in terms of what they like and what they do not like. Erikson's psychosocial theory emphasizes the emergence of self, the search for identity, the individual's relationship with others (Woolfolk, 2013). Preschool and elementary teachers who are traditionally trained take courses in child development where they learn about this process of identity and how to support children through different stages of their psychosocial development. The purposes of this study were to investigate the assumption that if preschool teachers are informed about identity then that would automatically translate to what preschool teachers know about science identity. 
Lave and Wenger (1991) agree students to develop identities through engaging with the practices and tasks of the science classroom. Science identity is defined by Carlone (1994) as demonstrating competent performance in relevant scientific practices with deep meaningful knowledge and understanding of science, and recognizing oneself and/or being recognized by others as a science person. Tan \& Calabrese-Barton (2007) expand on this definition by adding that this identity is constructed socially within communities of practice. Learning science in this community (of practice) then becomes "a process of becoming to be, of forging identities in activity" (Lave \& Wenger, 1991). This study was conducted as a way of examining what preschool teachers might know about young children's science identity and how that relates to their community of practice. The research questions were as follows: 1) How did teachers feel about science identity before the Sid the Science Kid episode? 2) How did they feel about science identity after the Sid the Science Kid episode?

\subsection{Background}

As preschool students encounter a school-like setting and the context of the classroom they are defining and expressing themselves by preferences and classroom behaviors. Carlone \& Johnson (2007) describe science identity as how individuals make meaning of science experiences and how society structures those possible meanings. Brickhouse and Potter (2001) established that a science-related identity does not also reflect the values of the school-mediated engagement or if the students do not have access to the resources they need to do well in science. A science-related identity becomes important when individuals draw upon successful participation in school science, despite the lack of resources in a home environment. One's personal science identity (Farland-Smith, 2009) is embedded within his or her science identity of his or her identities-in-practice. Identity construction is composed of science identity that is exhibited and revealed to others in a social setting. The identities-in-practice is the result of the external features one can see, such as classroom participation, etc. Science identity then, is the consideration of attitudes, feelings, and intellect is embedded within a particular context, such as a community of practice, the term personal science identity is based on the introspective nature of one's science identity. The likes and dislikes, whether they have an opportunity to rise to the surface or not, are dependent upon the community of practice and opportunities, including a person's self-efficacy and comfort level with science. For example, a child may like something and not know why or what situation informed her choice.

\subsection{Sid the Science Kid}

A popular show that highlights preschool science was selected for use in this study because it is an award winning show that focuses on one single science concept that is presented using Preschool Pathways to Science, a practical science readiness curriculum used in preschool classrooms. This television show 
was used as a clip to spur discussion with preschool teachers as the show contains a high amount of science content and substantial amounts of questioning. Sid the Science Kid is a 30-minute show, of the life of Sid a curious four-year-old. Sid asks questions about how things work and the world around him and he tries to answer these questions using scientific methods. The cast of the show is made up of his classmates (May, Gerald, and Gabriela) and his parents (Alice and Mort) who also engage in scientific investigations.

In each episode unfolds similarly, Sid wakes up with a question on his mind and he begins to investigate this question at breakfast. Then, as he prepares for school, he brings this question to pre-school, and on the playground he begins formalizing his research into the actual investigation phase with his friends. He then takes this question from the playground to the classroom and introduces it to his teacher, Susie. The day at pre-school revolves around investigating this same question. The episode concludes with Sid's grandmother picking him up and reinforcing what he has learned throughout the day.

Sid the Science Kid is unique in that it each of the 69 episodes are about a boy in preschool who investigates earth, life and physical science (Farland-Smith \& Chao, 2017). The episodes include topics relevant to developmentally appropriate to young scientists include: the body, force and motion, environmental systems, light and shadow, technology and engineering, tools and measurement, changes and transformation, senses, health, simple machines, backyard science, weather, and living things. Each episode's conceptual content connects to the National Science Standards (NRC, 1996), Cognitive Learning Theory, and preschool science curriculum, Preschool Pathways to Science (Gelman, Brenneman, Macdonald, \& Roman, 2010).

\subsection{Subjects}

Preschool teachers were identified for this study because no research exists on teachers' perceptions of science identity with this age group. Twelve teachers attending the faculty meeting were recruited for participation in this research study and all willingly participated.

\subsection{Methodology}

At the faulty meeting during late spring of a traditional school year the researcher administrated the survey. Teachers had approximately 10 minutes to complete the pre-survey and post survey. The surveys were placed in a marked envelope and the researcher left the room to ensure confidentiality. When the researcher returned a video clip of Sid the Science Kid was shown to teachers which took approximately 20 minutes. This show was selected for this study because of Sid's questioning strategies and the idea of scientific process within the realm of scientific methods developmentally appropriate for preschoolers.

Then, a post survey was given in the same way as the presurvey to ensure confidentiality. No tests either reliability, or validity were performed on the 
pre-survey or post survey questions to the video clip. Questions have been worded to avoid bias. Sid the Science Kid was specifically selected for this group of teachers as to create a discussion of preschool science. Each classroom was given $\$ 100$ to purchase materials in their classrooms related to science.

\subsection{Analysis and Results}

Teachers pre and post surveys were be coded by the researcher. The surveys were analyzed for themes, and the follow-up questions will also be transcribed and coded for themes. Themes occurring most often were analyzed for statistical significance.

\section{Pre-Survey}

Teachers were asked to respond to a rating scale of 1 (lowest) - 10 (highest). They were asked to draw a dot on the number that most closely correlates with how they would rate their classroom in terms of science engagement. All twelve teachers responded to the rating scale. The average response was a moderate 5.5 in terms of how this particular group of preschool teachers rated their classroom in terms of engagement.

Then, the preschool teachers were asked to describe what they knew about children's science identity formation and if and how it impacts their teaching. Half of the twelve preschool teachers admitted they did not know what children's science identity was. Two had undeterminable answers to the questions. The remaining four answers involved children doing hands-on science experiments and asking questions as to how it impacts their teaching.

The next question asked teachers to consider the biggest impact on a preschooler's science identity, classroom, media, or home. Three teachers reported media and home. One teacher reported media and school. Eight teachers listed all three; classroom, media and home.

The last set of question was focused on scientists, the preschool teachers if they mention the word "scientist" in their classroom. Describe the situations, if you do and the context. Six teachers said they do not mention the word scientist in their preschool classrooms. One reported they typically would not. Five preschool teachers said they would mention the word "scientist" when we they do experiments. When asked whether or not they have had a scientist visit their classroom. Seven teachers of the twelve reported they had never had a scientist visit their classroom. The remaining five teachers reported that a mixture of parents and a representative from the Metro Park (called the owl lady), and local university served as "scientists" in their classroom.

\section{Post Survey (Discussion Questions)}

After Sid the Science Kid excerpt was shown. Teachers answered the following questions in a group discussion. The questions are italicized below:

What kinds of things did you see teacher Susie doing that would support or 
improve Sid's science identity? Twelve out of 12 teachers spent the majority of time discussing this first question. The preschool teachers as a collective group understood very clearly from the Sid the Science episode the explicit teaching of science, yet admitted they did not focus on science in that same way. All of the 12 teachers asked many questions and felt like they could focus on science identity and role play more explicitly if they were trained it in. In essence, it made sense to them and was a genuine "aha" moment. All twelve teachers spent time discussing their knowledge of identity and admitted just never thought of science identity in particular or teaching it. It was the longest, deepest discussion. Teachers admitted they could improve their science learning centers to focus on science identity and also wanted to watch more episodes of Sid the Science Kid to learn different ways to teach science in general.

What kinds of ways were Susie's classroom set up to facilitate science learning? Teachers discussed that Susie had students working as if they were scientists, asking questions, and formulating ideas. She had students working as if they were scientists, asking questions, formulating ideas, testing results and outcomes. Teachers noted the tent Sid made in the episode, and how free exploration was present in their rooms yet missing science tools in their rooms. All twelve teachers fundamentally believed in play, yet when it came down to it they were not providing science exploration specific to play or opportunities for children to role play being scientists.

Since the teachers sent the majority of the discussion time on the first question, there were very little answers and discussions for the last few questions. Describe one way your classroom is like Susie's. Teachers spent time reflecting on their science centers and the tools they included. These centers were designated places for science which changed during the year based on seasons. Describe one way your classroom is not like Susie's. All twelve teachers were quick to respond that on Sid the Science Kid, teacher Susie only had four children in her class.

\section{Conclusion/Discussion}

Recall, this study was designed to answer these questions. Each of these questions will be discussed.

1) How did teachers feel about science identity before the Sid the Science Kid episode?

Teacher surveys administered before Sid the Science Kid episode and post survey discussion reveal that most of the teachers were unsure of what science identity was in relation to their preschool children. Several posed questions about the survey question back to the researcher about the difference between identity and science identity in need of further clarification.

2) How did they feel about science identity after the Sid the Science Kid episode?

Teachers were more aware of and had a fruitful and lengthy discussion of 
what science identity could be after watching the episode. They mentioned career choice and career education. They also mentioned that children naturally like science, and if they knew more about how to consider science identity with their pedagogical practice and room set up, they would consider recommendations and implement suggestions.

\section{Implications}

The notable conclusions were a result of this study 1) preschool teacher's lack of awareness and understanding of science identity; and 2) preschool teacher's appreciation and willingness of students' to role play being a scientist, but little understanding of why this role play is beneficial.

Would preschool teachers consider teaching lessons focusing on student's science identity if they had specific guidance and explicit discussions about it? In this sample of teachers it was observed that they did not know what science identity was, therefore how could they consider it in their teaching? It cannot be developed and nurtured if it is not a consideration on their classroom practice. According to the Next Generation of Science Standards (NGSS Lead States, 2013) the call for scientifically literate students and their understanding of the science processes such as the benefits of considering irreversible change can motivate young children who experience such pleasure and fulfillment of discovery with the hopes that they will want to savor it again and again. Early investment and exposure to science can inspire many years of discovery. In this way, the content in Sid is both meaningful and relevant to the everyday lives of young children and their teachers. In this way the science content is framed in relatable ways to its characters yet investigated through the nature of science, through posing questions, investigating objects and events that can be directly observed and explored. There is a lack of professional development for this level in general, and even less in terms of science pedagogy instruction.

\section{References}

Brickhouse, N. W., \& Potter, J. T. (2001). Young Women's Science Identity Information in an Urban Context. Journal of Research in Science Teaching, 38, 965-980. https://doi.org/10.1002/tea.1041

Carlone, H. B. (1994). The Cultural Production of Science in Reform-Based Physics: Girls' Access, Participation, and Resistance. Journal of Research in Science Teaching, 37, 871-889.

Carlone, H. B., \& Johnson, A. (2007). Understanding the Science Experiences of Successful Women of Color: Science Identity as an Analytic Lens. Journal of Research in Science Teaching, 44, 1187-1218. https://doi.org/10.1002/tea.20237

Farland-Smith, D. (2009). How Does Culture Shape Students' Perceptions of Scientists? Cross-National Comparative Study of American and Chinese Elementary Students. Journal of Elementary Science Education, 21, 23-42.

https://doi.org/10.1007/BF03182355

Farland-Smith, D., \& Chao, T. (2017). What Are My Children Watching? Analyzing the Scientific \& Mathematical Questions of Preschool Television Shows Using Process 
Skills. Creative Education, 8, 847-856. https://doi.org/10.4236/ce.2017.86061

Gelman, R., Brenneman, K., Macdonald, G., \& Roman, M. (2010). Preschool Pathways to Science (PrePS): Facilitating Scientific Ways of Thinking, Talking, Doing, and Understanding. Baltimore, MD: Brookes Publishing.

Lave, J., \& Wenger, E. (1991). Situated Learning: Legitimate Peripheral Participation. Cambridge: Cambridge University Press. https://doi.org/10.1017/CBO9780511815355

NGSS Lead States (2013). Next Generation Science Standards: For States, by States. Washington DC: The National Academies Press.

NRC (National Research Council) (1996). National Science Education Standards. Washington DC: National Academy Press.

Tan, E., \& Calabrese-Barton, A. (2007). From Peripheral to Central, the Story of Melanie's Metamorphosis in an Urban Middle School Science Class. Science Education, 92, 567-590. https://doi.org/10.1002/sce.20253

Woolfolk, A. (2013). Educational Psychology (13th ed.). Upper Saddle River, NJ: Pearson. 